This item was submitted to Loughborough's Research Repository by the author.

Items in Figshare are protected by copyright, with all rights reserved, unless otherwise indicated.

\title{
Shirasu Porous Glass membrane emulsification: characterisation of membrane structure by high-resolution X-ray microtomography and microscopic observation of droplet formation in real time
}

\section{PLEASE CITE THE PUBLISHED VERSION}

http://dx.doi.org/10.1016/j.memsci.2007.06.067

\section{PUBLISHER}

(C) Elsevier

\section{VERSION}

AM (Accepted Manuscript)

\section{LICENCE}

CC BY-NC-ND 4.0

\section{REPOSITORY RECORD}

Vladisavljevic, Goran T., Isao Kobayashi, Mitsutoshi Nakajima, Richard A. Williams, Masataka Shimizu, and Tadao Nakashima. 2012. "Shirasu Porous Glass Membrane Emulsification: Characterisation of Membrane Structure by High-resolution X-ray Microtomography and Microscopic Observation of Droplet Formation in Real Time". figshare. https://hdl.handle.net/2134/10154. 
This item was submitted to Loughborough's Institutional Repository (https://dspace.lboro.ac.uk/) by the author and is made available under the following Creative Commons Licence conditions.

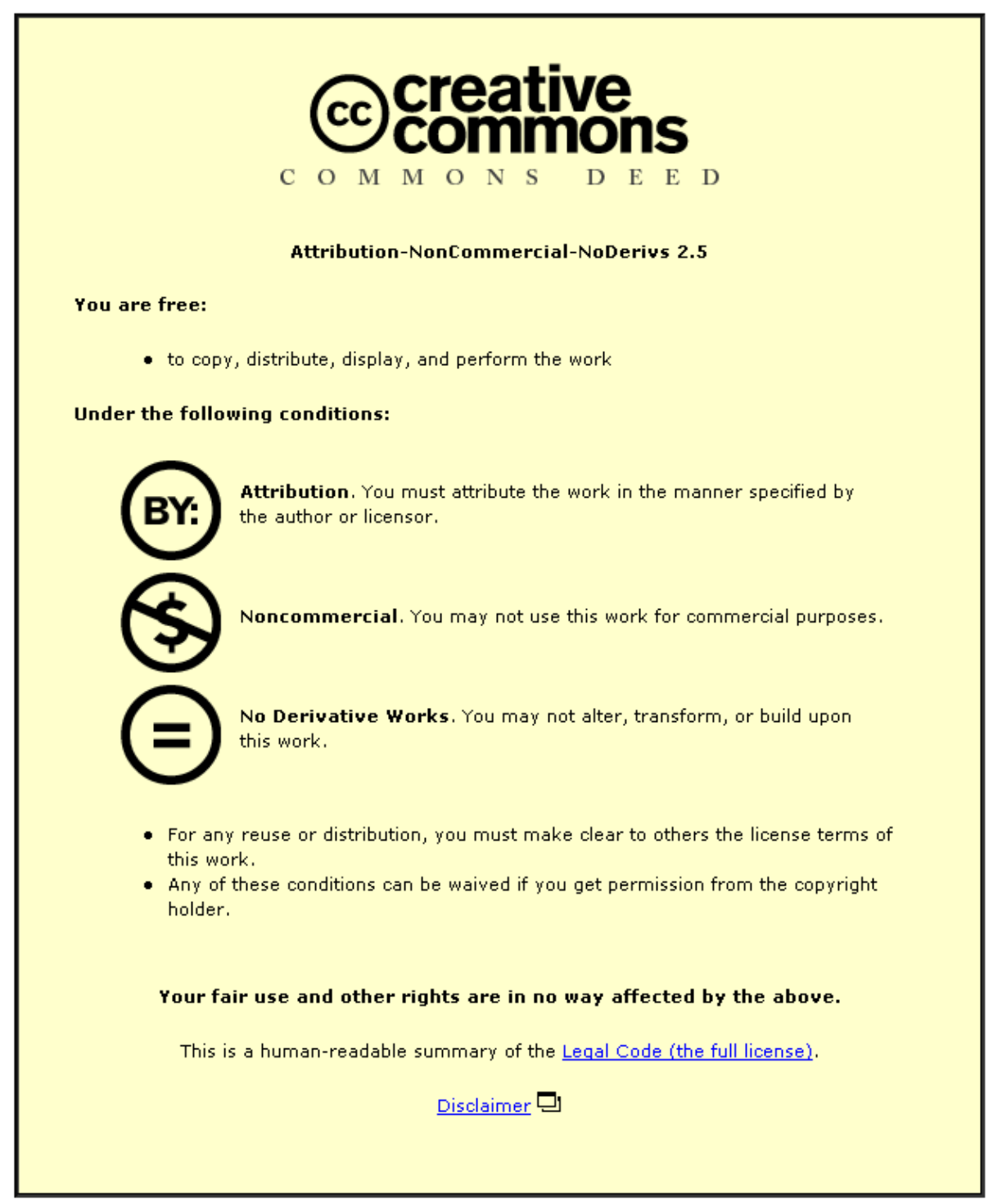

For the full text of this licence, please go to: http://creativecommons.org/licenses/by-nc-nd/2.5/ 


\title{
Shirasu Porous Glass membrane emulsification: Characterisation of membrane structure by high-resolution X-ray microtomography and microscopic observation of droplet formation in real time
}

\author{
Goran T. Vladisavljevića, ${ }^{\mathrm{a}}$, Isao Kobayashi ${ }^{\mathrm{b}}$, Mitsutoshi Nakajima ${ }^{\mathrm{b}}$, \\ Richard A. Williams ${ }^{\mathrm{c}}$, Masataka Shimizu ${ }^{\mathrm{d}}$, Tadao Nakashima ${ }^{\mathrm{e}}$ \\ ${ }^{a}$ Chemical Engineering Department, Loughborough University, Loughborough, Leicestershire LE11 3TU, United Kingdom \\ ${ }^{\mathrm{b}}$ Food Engineering Division, National Food Research Institute, Kannondai 2-1-12, Tsukuba, Ibaraki 305-8642, Japan \\ ${ }^{c}$ Institute of Particle Science \& Engineering, School of Process, Environmental \& Materials Engineering, Clarendon Road, \\ University of Leeds, Leeds LS2 9JT, United Kingdom \\ d Miyazaki Prefectural Industrial Technology Center, 16500-2 Higashi-Kaminaka, Sadowara, Miyazaki 880-0303, Japan

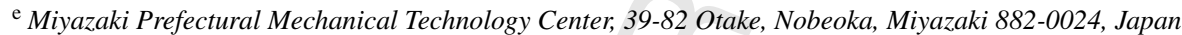

Received 28 April 2007; received in revised form 19 June 2007; accepted 22 June 2007

\begin{abstract}
The microstructure of Shirasu Porous Glass (SPG) membrane has been investigated using metallographic microscope and high-resolution X-ray microtomography (XMT) and the obtained results are compared with Hg-porosimetry data. The porosity in 600 cross sections analysed by highresolution XMT was found to vary in a narrow range between 52.5 and $57.4 \%$ with a mean value of $55.1 \%$. The membrane microstructure looks similar on SEM and XMT images with tortuous, interconnected cylindrical pores extending in all directions within the membrane. The formation of $\mathrm{O} / \mathrm{W}$ and $\mathrm{W} / \mathrm{O} / \mathrm{W}$ emulsion droplets have been observed in real time using SPG or Microporous Glass (MPG) membrane disks with a mean pore size between 10.2 and $16.2 \mu \mathrm{m}$. The quality of video recordings was much better when membrane surface was finely polished with diamond paste, although it did not affect the droplet formation behaviour. The droplets formed at the same pore were highly monodispersed and detached in regular time intervals, but this time interval showed significant variations for different pores. The SDS-stabilised droplets were detached from the pores as soon as they were formed, due to strong electrostatic repulsions between anionic droplets and negatively charged SPG surface. The Tween 80-stabilised droplets were kept attached to the membrane surface after formation, before being pushed away by the next droplet formed at the same pore. Under the same conditions the SDS-stabilised droplets were smaller than the droplets stabilised by Tween 80 .
\end{abstract}

(C) 2007 Elsevier B.V. All rights reserved.

Keywords: Membrane emulsification; Shirasu Porous Glass membrane; Droplet generation; X-ray microtomography; Metallographic microscope

\section{Introduction}

The manufacturing process for Shirasu Porous Glass (SPG) membrane from "Shirasu", lime, and boric acid has been developed in the 1980s by Nakashima et al. [1,2]. Shirasu is a volcanic ash that occurs naturally in the southern areas of Kyushu, Japan containing about $86 \%$ of $\mathrm{SiO}_{2}$ and $\mathrm{Al}_{2} \mathrm{O}_{3}$ in addition to some other inorganic oxides. The main difference in chemical composition between SPG and porous Vycor glass is that SPG

\footnotetext{
* Corresponding author. Tel.: +44 1509222 518; fax: +44 1509223923.

E-mail address: G.Vladisavljevic@lboro.ac.uk (G.T. Vladisavljević).
}

contains less $\mathrm{SiO}_{2}$ and more $\mathrm{Al}_{2} \mathrm{O}_{3}$ and other minor components. SPG membrane has been extensively investigated over the past two decades as a dispersion medium in emulsification and gas dispersion processes [3-9]. In 'direct' membrane emulsification process, one immiscible liquid (the disperse phase) is forced through the membrane into another immiscible liquid (the continuous phase) and microdroplets are formed at the interface between the membrane surface and the continuous phase. Several reviews focused on different aspects of membrane emulsification technology are available [10-15], as well as mathematical models for prediction of resultant droplet size as a function of pore size, physicochemical properties of the dispersed system, and operating parameters [16-19]. van der

0376-7388/\$ - see front matter (c) 2007 Elsevier B.V. All rights reserved.

doi:10.1016/j.memsci.2007.06.067

Please cite this article in press as: G.T. Vladisavljević et al., Shirasu Porous Glass membrane emulsification: Characterisation of membrane structure by high-resolution X-ray microtomography and microscopic observation of droplet formation in real time, J. Membr. Sci. (2007), doi:10.1016/j.memsci.2007.06.067 
22 Graaf et al. [10] summarized the advantages and disadvantages 23 of membrane emulsification in relation to the production of 24 double emulsions. Joscelyne and Trägårdh [11] reviewed the 25 experimental studies focused on the investigation of the effects 26 of various operating and process parameters, such as mem${ }_{27}$ brane type, average pore size and porosity, cross-flow velocity, 28 transmembrane pressure and emulsifier, on the direct mem29 brane emulsification. Nakashima et al. [12] presented industrial 30 applications of membrane emulsification technology ranging 31 from low-fat food spreads and polymer microspheres for liq32 uid crystal display to drug delivery systems. Vladisavljević 33 and Williams [13] reviewed the expanding opportunities for 34 manufacturing functional particulate products using membrane 35 emulsification. Gijsbertsen-Abrahamse et al. [15] discussed the 36 status of cross-flow membrane emulsification and outlook for 37 industrial application with special emphasis on the membrane $38 \quad$ choice and optimization.

SPG membrane has been successfully used for the sizecontrolled production of uniform multiple emulsion droplets [20-22], solid lipid microcapsules [23], polymer microspheres [24], colloidal silica particles [25], solder metal microparticles [26], solid-in-oil-in-water (S/O/W) dispersions [27], and nanobubbles [28]. Under dripping regime, the mean particle size of resultant emulsion is typically three to four times larger than the mean pore size of SPG membrane used and the shear stress at the membrane surface should be at least $10 \mathrm{~Pa}$ to assist in droplet detachment from the pores [8]. The transmembrane pressure should be kept lower than five times the capillary pressure to prevent the transition from dripping to a continuous jet regime [8].

In order to gain deep insight into droplet formation behaviour in membrane emulsification, the process can be observed in real time using microscope attached to a CCD camera. This is a standard experimental approach in microfluidic devices for droplet generation [29]. Abrahamse et al. [30] visualized droplet formation at a small-size micro-engineered membrane with the mean pore size of $7 \mu \mathrm{m}$ and Kobayashi et al. [31] observed droplet formation at a polycarbonate track-etch membrane filter. However, SPG membrane emulsification devices for routine manufacturing applications are usually equipped with tubular membranes of much larger dimensions than micro-engineered microsieves, which complicates or completely excludes the visualization of droplet generation. Yasuno et al. [32] first visualized droplet formation at a flat SPG membrane with the mean pore size of $15 \mu \mathrm{m}$. This work was restricted to the formation of $\mathrm{O} / \mathrm{W}$ emulsion droplets stabilised by SDS (sodium dodecyl sulfate). This work is the first attempt to observe in real time formation of multiple emulsion droplets at SPG membrane and to investigate the effect of different emulsifiers (SDS and Tween 80) on the droplet formation characteristics. In addition, the role of the roughness of membrane surface on the quality of microscopic images will be demonstrated which might be of great significance in future work.

The main advantage of using SPG membrane in liquid and gas dispersion processes is that it contains highly uniform pores. It can be fabricated with the mean pore size over a wide range between $50 \mathrm{~nm}$ and $20 \mu \mathrm{m}$ and the membrane surface can easily

be rendered hydrophobic, if needed [33]. The microstructure of SPG membrane has been determined by scanning electron microscopy, transmission electron microscopy and mercury porosimetry $[33,34]$. In this work, the internal structure of SPG membrane has been investigated for the first time using X-ray microtomography (XMT), which allows reconstructions of the 3D internal structure of objects non-destructively without any prior preparation (cutting, coating or vacuum treatment). The aim of using XMT in this work has been to estimate the uniformity of the internal structure of SPG membrane by measuring the numerical parameters such as porosity and number of pores per unit area in different $2 \mathrm{D}$ areas inside the membrane and to compare these values to those estimated by microscopy and $\mathrm{Hg}$ porosimetry.

\section{Experimental}

\subsection{Real time microscopic observation}

The membrane emulsification process was observed in real time using the experimental set-up sketched in Fig. 1. A SPG membrane was placed between the two transparent acryl-plates using rubber spacers to form the upper and lower compartment at both sides of the membrane. The continuous phase (aqueous solution of emulsifier) flowed in a cross flow through the upper compartment without any recirculation, while the dispersed phase (soybean oil or W/O emulsion) was injected from the lower compartment using a syringe pump (Pump 11, Harvard, Holliston, USA). The flow rate of the dispersed phase was constant at $0.1-5 \mathrm{ml} \mathrm{h}^{-1}$, corresponding to the transmembrane flux between 0.47 and $23.71 \mathrm{~m}^{-2} \mathrm{~h}^{-1}$. The thickness of the continuous phase film between the membrane surface and the upper transparent plate was $3.6 \mathrm{~mm}$.

A microscope video system consisting of an inverted metallographic microscope (MS-511-M, Seiwa Optical Co.), a high-resolution color CCD camera (LCL-211H, Watec America Corp. with an image resolution of 480 TV lines and a time

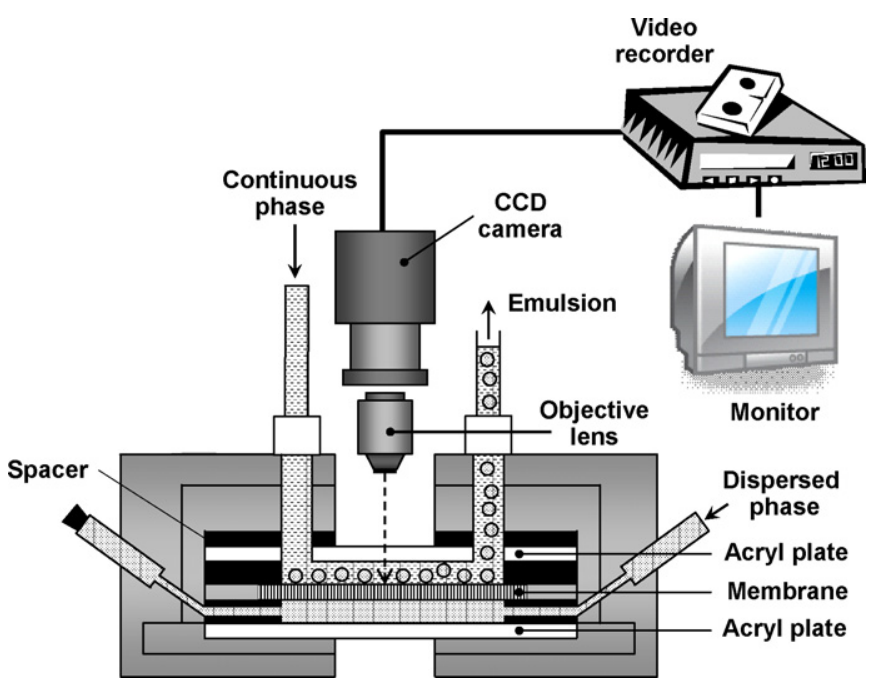

Fig. 1. Experimental set-up for microscopic observation of droplet formation in real time. 
resolution of 30 frames per second) and a $20 \mathrm{in.} \mathrm{monitor} \mathrm{(PVM-}$ $20 \mathrm{M} 4 \mathrm{~J}$, Sony) has been used for the observation of droplet formation and membrane surface. Metallographic microscopes employs a type of illumination called vertical illumination in which the light source is inserted through the microscope tube below the eyepiece by means of a beam splitter. The position of the objective lens was precisely controlled by the XY-stage. The total magnification on the monitor was 2000 . The process was recorded on a video recorder (HR-DVS3, JVC) using Mini DV video tapes. The MPEG video clips were created from the recorded tapes using the Giga Pocket Ver. 2.0 software (Sony). The JPEG images with a resolution of $1500 \times 1125$ pixels were captured using the $\mathrm{V}$-shot photo grabber (Canopus). The droplet size was estimated using the WinRoof image analysis software (Mitani Co.). The size of each pixel in the captured JPEG images was approximately $0.2 \mu \mathrm{m}$ and the calibration was conducted using a microscopic image of the eyepiece graticule with a minor division of $10 \mu \mathrm{m}$, taken at the same magnification as the images of droplets formation. The droplet diameter was calculated automatically by the WinRoof software based on three points selected manually on the droplet's edge and the pixel size. For all experimental conditions at least 100 droplets were counted and measured from at least 10 random active pores. The number weighted mean droplet diameter $d_{\mathrm{n}}$ at specified operating conditions was calculated using the equation:

$d_{\mathrm{n}}=\frac{\sum_{i=1}^{n} d_{i} v_{i}}{\sum_{i=1}^{n} v_{i}}=\frac{\sum_{i=1}^{n} d_{i} / t_{i}}{\sum_{i=1}^{n}\left(1 / t_{i}\right)}$

where $d_{i}$ is the mean droplet diameter at the $i$ th active pore, $v_{i}$ the mean frequency of droplet generation at the $i$ th active pore, $t_{i}$ the mean time interval between two consecutive droplets at the $i$ th active pore, and $n$ is the number of active pores observed $(n \geq 10)$. The total number of active pores was estimated from the equation:

$N_{\mathrm{a}}=\frac{6 Q_{\mathrm{d}} n}{\pi \sum_{i=1}^{n} d_{i}^{3} v_{i}}$ where $Q_{\mathrm{d}}$ is the dispersed phase flow rate through the membrane. The total number of pores on the membrane surface was calculated from the equation [33]:

$N=\frac{4 A_{\mathrm{m}} \varepsilon}{\pi d_{\mathrm{p}}^{2} \xi}$

where $A_{\mathrm{m}}$ is the effective membrane area, $\varepsilon$ the membrane porosity, $d_{\mathrm{p}}$ the mean pore size, and $\xi$ is the mean pore tortuosity. For SPG membrane, $\varepsilon$ was found to vary between 0.5 and 0.6 and $\xi=1.28$ [33]. From Eqs. (2) and (3), the proportion of active pores is given by:

$k=\frac{N_{\mathrm{a}}}{N}=\frac{3 d_{\mathrm{p}}^{2} \xi Q_{\mathrm{d}} n}{2 \varepsilon A_{\mathrm{m}} \sum_{i=1}^{n} d_{i}^{3} v_{i}}=\frac{3 d_{\mathrm{p}}^{2} \xi J_{\mathrm{d}} n}{2 \varepsilon \sum_{i=1}^{n} d_{i}^{3} v_{i}}$

\subsection{X-ray microtomography for the static observation of membrane}

X-ray microtomographic measurements of SPG membrane have been carried out using a desk-top microscanner (SkyScan, model 1072, Aartselaar, Belgium) with a maximum pixel resolution of 3-4 $\mu \mathrm{m}$. This instrument consists of a microfocus sealed $\mathrm{X}$-ray tube, a precision object manipulator with two translations and one rotation, an X-ray CCD-camera, and an external computer. SkyScan's Tview software has been used to display and analyse microtomographic cross sections [35,36]. This software can calculate the porosity, average pore size and number of pores for any selected area in the cross-section and for any crosssection within a sample. A sample of SPG membrane analysed and a typical X-ray image obtained is shown in Fig. 2. More than 600 XMT images of the membrane cross-section perpendicular to the $z$-axis has been viewed and analysed over the height of $2.2 \mathrm{~mm}$ at the pixel resolution of 3-4 $\mu \mathrm{m}$. The membrane was isotropic, which was confirmed by XMT analysis of different samples of the same SPG membrane (the results are not shown here). The shape and size of pores is not affected by the orientation of the cross-section, because the pores extend randomly in all directions. Kukizaki and Goto [37] recently developed an
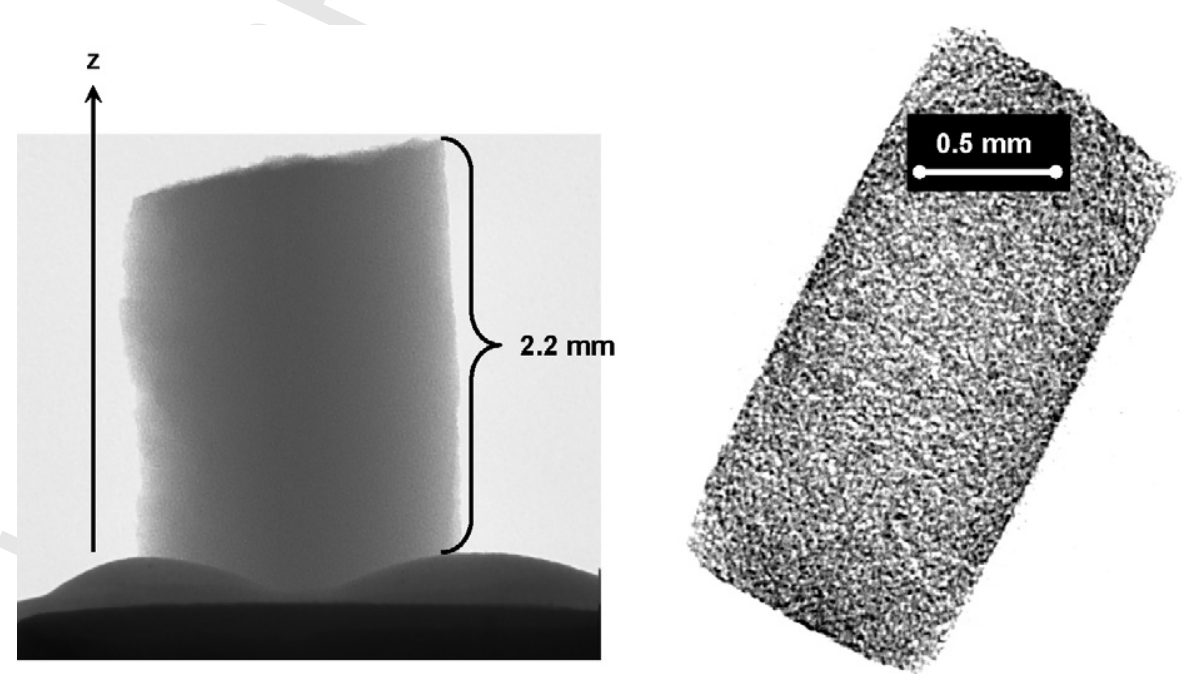

Fig. 2. Sample of SPG membrane for X-ray microtomography and a typical cross-section through the internal microstructure of membrane.

Please cite this article in press as: G.T. Vladisavljević et al., Shirasu Porous Glass membrane emulsification: Characterisation of membrane structure by high-resolution X-ray microtomography and microscopic observation of droplet formation in real time, J. Membr. Sci. (2007), doi:10.1016/j.memsci.2007.06.067 
(a)

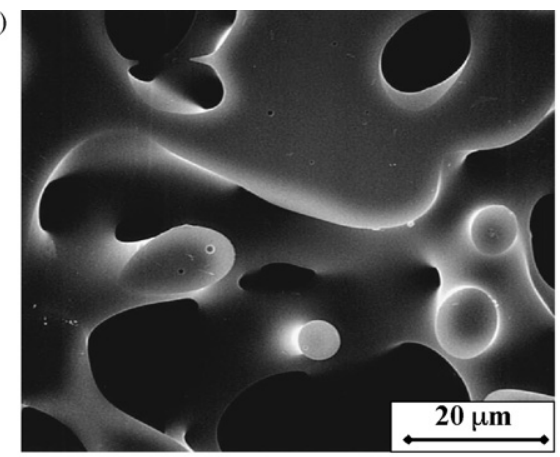

(b)

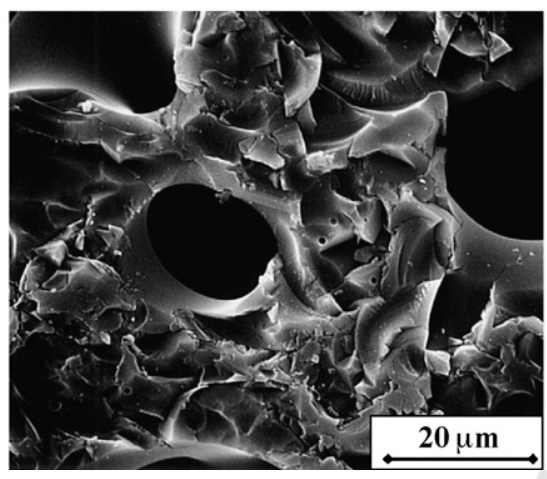

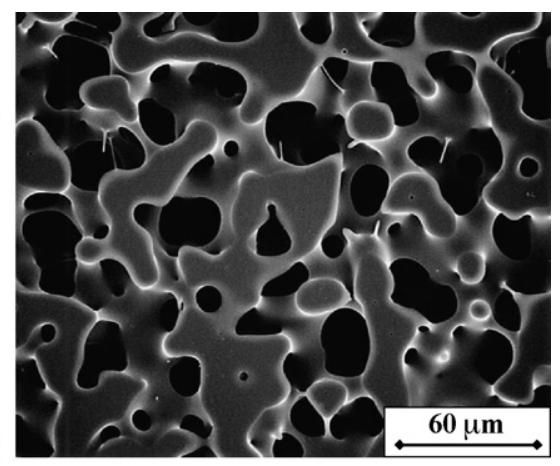

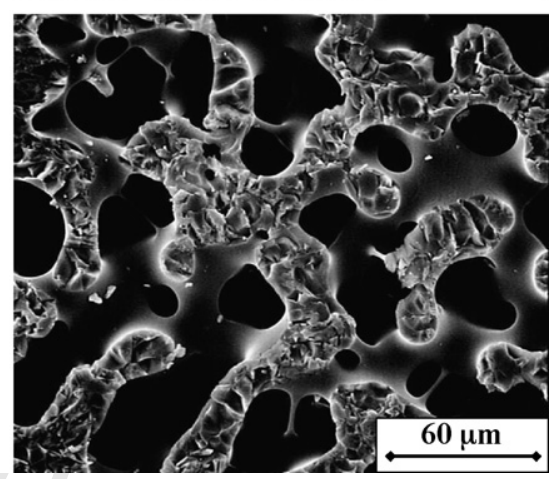

Fig. 3. Scanning electron micrographs of SPG membrane with a polished and unpolished (rough) surface. (a) Polished SPG surface (mean pore size $=15.0 \mu \mathrm{m}$ ) and (b) unpolished MPG surface (mean pore size $=16.2 \mu \mathrm{m}$ ).

asymmetric SPG membrane, but in this work only symmetric, i.e. isotropic SPG membranes were used.

\subsection{Membranes}

The experiments have been carried out using flat SPG or Microporous Glass (MPG) membrane disks with an effective cross-sectional area of $2.11 \mathrm{~cm}^{2}$ and a mean pore size in the range between 10.2 and $16.2 \mu \mathrm{m}$. The SPG membrane disks fabricated at the Industrial Technology Center Miyazaki with a mean pore size of 10.2 or $15 \mu \mathrm{m}$ were polished with diamond paste to obtain a smooth surface suitable for microscopic observation. The MPG membrane with a mean pore size of $16.2 \mu \mathrm{m}$ supplied from the ISE Chemical Industries Co. Ltd. was not polished, as can be seen in Fig. 3. The mean pore size of all membranes was measured by mercury intrusion porosimetry using a pore sizer (model 9320, Shimadzu, Japan) with a resolution of 132 size channels in the pore size range of 0.0355 $105.882 \mu \mathrm{m}$.

\subsection{Emulsion composition}

The dispersed phase in oil-in-water $(\mathrm{O} / \mathrm{W})$ emulsions was pure soybean oil supplied by Wako Pure Chemical Industries Ltd. (Japan) with a density of $920 \mathrm{~kg} \mathrm{~m}^{-3}$ and viscosity of $53 \mathrm{mPa}$ s at $298 \mathrm{~K}$ and the continuous phase was an aqueous solution containing $1 \mathrm{wt} \%$ SDS (sodium dodecyl sulfate) or $1 \mathrm{wt} \%$ Tween 80 (polyoxyethylene (20) sorbitan monooleate). In multiple water-in-oil-in-water $(\mathrm{W} / \mathrm{O} / \mathrm{W})$ emulsions the continuous phase was an aqueous solution containing $1 \mathrm{wt} \%$ SDS or $1 \mathrm{wt} \%$ Tween 80 and the disperse phase was a submicron-sized water- in-oil (W/O) emulsion with 30 vol\% of water phase prepared using a microfluidizer (model M-110E/H, MFIC Corporation, MA, USA) distributed by Mizuho Industrial Co. Ltd. (Osaka, Japan). The oil phase in W/O/W emulsions was a solution containing $5 \mathrm{wt} \%$ polyglycerol polyricinoleate (PGPR) and $95 \mathrm{wt} \%$ soybean oil.

\section{Results and discussion}

\subsection{Microstructure of SPG membrane}

A SEM image of membrane surface and XTM image of the interior structure for the same piece of SPG membrane under the same magnification is shown in Fig. 4. The membrane microstructure looks similar on both images with tortuous, interconnected cylindrical pores extending in all directions within the membrane. Some of the pore cross sections are not circular, because the pores do not always intersect with the cross-sectional area at a right angle, and the pore junctions also appear in the micrographs. A metallographic microscope image of polished membrane surface with a mean pore size of $15 \mu \mathrm{m}$ is shown in Fig. 5. The pores are visible as tortuous dark contours on a bright non-porous glass surface. The pore sizes estimated from the micrograph in Fig. 5 by using image analysis techniques are roughly in the range from 9 to $24 \mu \mathrm{m}$. From the pore size distribution curve shown in Fig. 5, it can be seen that 80 vol.\% of the pores are in the range from 10.9 to $18.9 \mu \mathrm{m}$. Approximately 76 circles with a diameter of $15 \mu \mathrm{m}$ can be arranged inside the dark regions in Fig. 5, from which it can be estimated that there are approximately 76 pores on the micrograph. Since the area shown on the micrograph is $202 \mu \mathrm{m} \times 152 \mu \mathrm{m}$, 


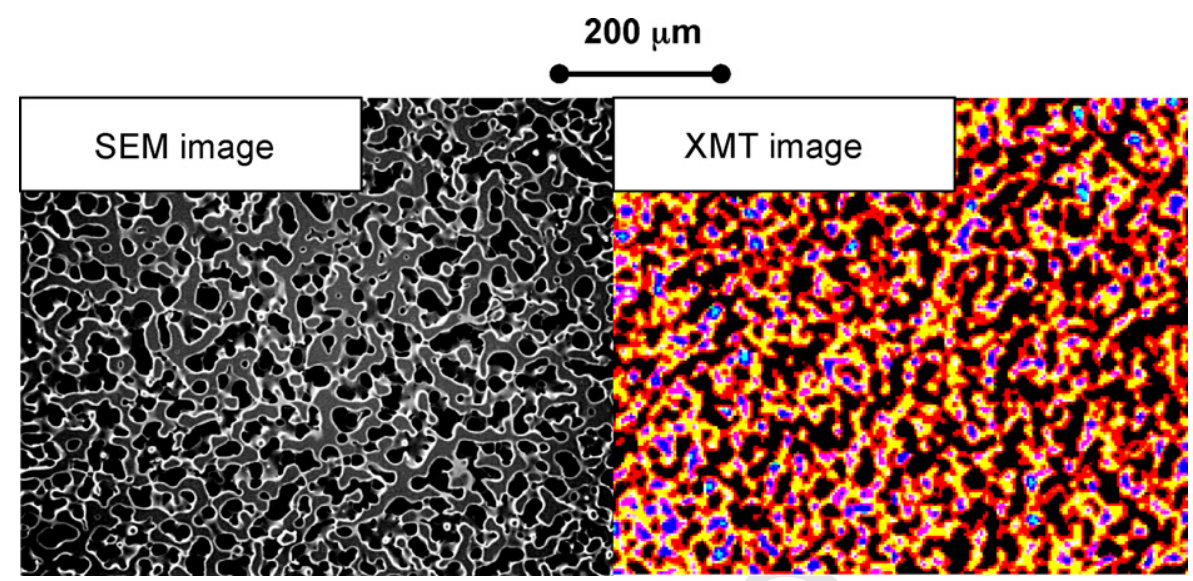

Fig. 4. Two images of the same piece of SPG membrane with a polished surface and a mean pore size of $15 \mu \mathrm{m}$, taken with scanning electron microscope and X-ray microscanner. The SEM image shows the membrane surface, whereas the XMT image shows the interior of the membrane.

the number of pores per unit cross-sectional area $N / A_{\mathrm{m}}$ is equal to: $76 /\left(202 \times 152 \times 10^{-12}\right)=2.48 \times 10^{9} \mathrm{~m}^{-2}$. For SPG membrane in the whole range of the mean pore sizes, $N / A_{\mathrm{m}}$ is related to the mean pore size $d_{\mathrm{p}}$ by the equation: $N / A_{\mathrm{m}}=0.56 d_{\mathrm{p}}^{-2}$, where $N / A_{\mathrm{m}}$ is in $\mathrm{m}^{-2}$ and $d_{\mathrm{p}}$ is in $\mathrm{m}$ units [33]. For the SPG membrane of interest $d_{\mathrm{p}}=15 \times 10^{-6} \mathrm{~m}$ and the above equation gives $N / A_{\mathrm{m}}=2.48 \times 10^{9} \mathrm{~m}^{-2}$, which is in excellent agreement with the $N / A_{\mathrm{m}}$ value estimated from Fig. 5. However, it is important to note that the suggested method provides only a rough estimation of the pore density due to many limitations.

Fig. 6 shows the fluctuations in $\varepsilon, N / A_{\mathrm{m}}$, and $d_{\mathrm{p}}$ in the $z$ direction for the sample of SPG membrane shown in Fig. 2. The porosity $\varepsilon$ was in the range between 52.5 and $57.4 \%$ with a mean value of $55.1 \%$, which corresponded very well with previously reported porosity values for SPG membrane. The fluctuations in the pore size, the pore density and porosity from one cross-section to another are rather small, suggesting that the investigated sample contains no large voids or cracks. Vladisavljević and Schubert [4] using pycnometry obtained a porosity between 53 and $60 \%$ for SPG membranes with $d_{\mathrm{p}}$ between 0.4 and $6.6 \mu \mathrm{m}$, whereas Vladisavljević et al. [33] using $\mathrm{Hg}$ porosimetry obtained $\varepsilon$ in the range from 50.4 to $58.1 \%$ for $d_{\mathrm{p}}=0.4-20.3 \mu \mathrm{m}$. It is important to note that both techniques give only an average membrane porosity. As shown in-Fig. 5 त the local mean pore size $d_{\mathrm{p}}$ ranged between 18 and $21 \mu \mathrm{m}$, which was higher than the value of $15 \mu \mathrm{m}$, obtained using $\mathrm{Hg}$ porosimetry data. It was probably because pore junctions were recognized by Tview software as a single large pore rather then two separate smaller pores. As a result of that, the number of pores per unit cross-sectional area has been underestimated. For
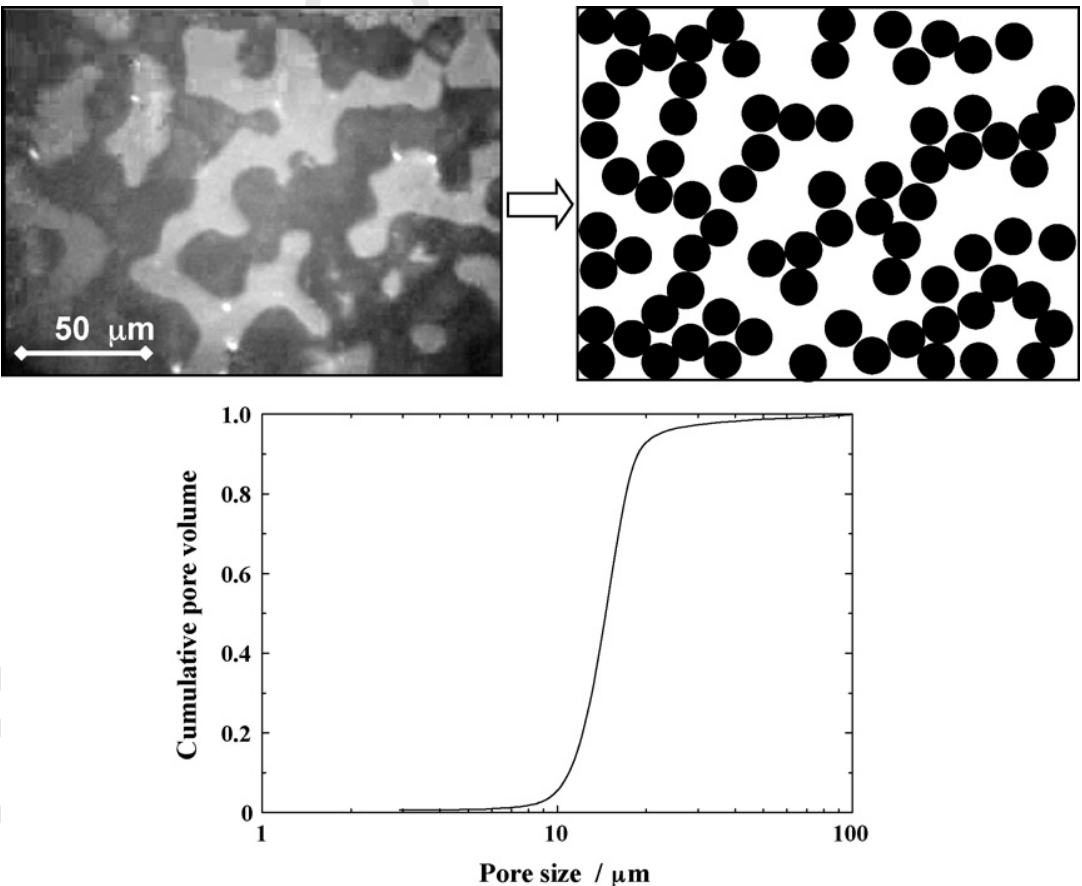

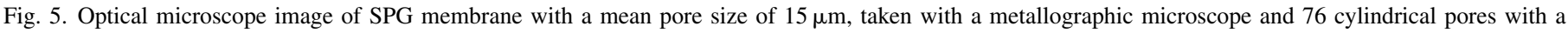
diameter of $15 \mu \mathrm{m}$ that can be drawn within dark contours. The pore size distribution curve for the given membrane obtained by Hg porosimetry is also presented.

Please cite this article in press as: G.T. Vladisavljević et al., Shirasu Porous Glass membrane emulsification: Characterisation of membrane structure by high-resolution X-ray microtomography and microscopic observation of droplet formation in real time, J. Membr. Sci. (2007), doi:10.1016/j.memsci.2007.06.067 

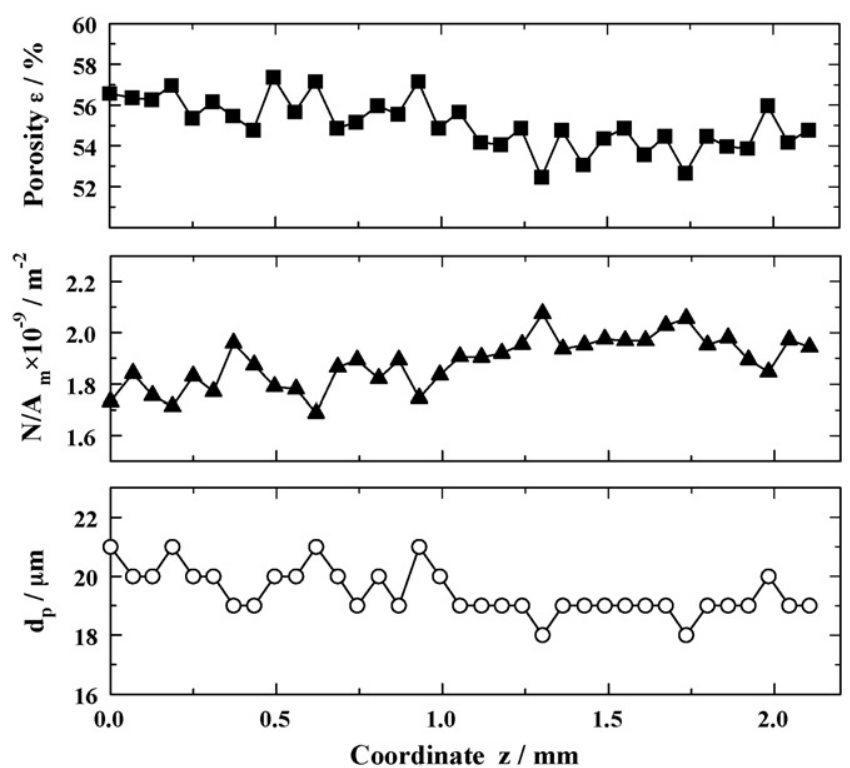

Fig. 6. Variations in membrane porosity, number of pores per unit crosssectional area and mean pore size at different cross sections within the sample of SPG membrane shown in Fig. 2.

example, $N / A_{\mathrm{m}}$ in Fig. 6 was in the range of $(1.7-2.1) \times 10^{9} \mathrm{~m}^{-2}$ for $z=0-2.2$, whereas the value of $2.48 \times 10^{9} \mathrm{~m}^{-2}$ was calculated from the equation $N / A_{\mathrm{m}}=0.56 d_{\mathrm{p}}^{-2}$. As shown in Fig. 7, the experimental XMT data points are close to the theoretical straight line with the equation: $N / A_{\mathrm{m}}=0.56 d_{\mathrm{p}}^{-2}$.

\subsection{Visualization of droplet formation at SPG membrane}

Microscopic images of the unpolished MPG membrane were unclear and pores could not be distinguished from non-porous glass regions, as can be seen in Fig. 8b. It is a consequence of the reflection of light beam from a rough membrane surface at different angles. For making high quality photos like in Fig. 8a, it was necessary to use SPG membranes with a polished surface. All photos in Fig. 9 are made using a polished SPG membrane with the mean pore size of $15 \mu \mathrm{m}$. Micrographs (a), (b), and (d) have been taken at relatively low droplet generation rate between 0.062 and 0.21 droplets per second, i.e. between 16.1 and $4.8 \mathrm{~s} /$ droplet. Several Tween 80 stabilised droplets attached to the membrane surface can be seen in each photo. Micrograph

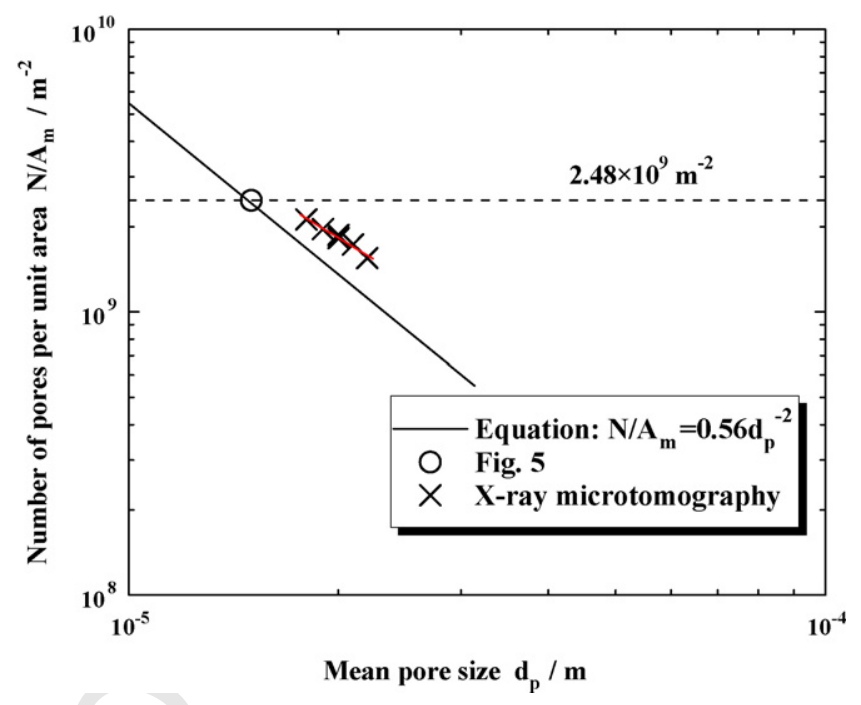

Fig. 7. Number of pores per unit cross-sectional area of SPG membrane estimated by $\mathrm{Hg}$ porosimetry and X-ray microtomography.

9(c) shows rapid generation of SDS-stabilised droplets at a rate of about 10 droplets per second. Five uniform droplets formed one after the other at the pore 2 and three uniform droplets formed at the pore 1 can be seen in the figure. After formation, the droplets were carried away by the continuous phase in the direction shown with a large arrow. The distance between the neighboring droplets is almost the same, indicating that the time interval between generation of two consecutive droplets was virtually the same.

Even if droplets formed at the neighboring pores contacted each other no coalescence was observed. The following problems in droplet formation have been identified: (i) formation of small droplets of sizes comparable to the pore size, as shown in Fig. 9(f); (ii) formation of very large droplets of sizes several times greater than the mean droplet size (Fig. 9(e)). The formation of droplets several times smaller or larger than the mean droplet size poses a problem, because it largely decreases the degree of monodispersity and leads to multi-modal particle size distribution (bi- or even tri-modal). Small droplets were probably formed as a result of the breakup of oil threads inside the pores by capillary instability, similar to the mechanism postulated in premix membrane emulsification [21]. It is based on the
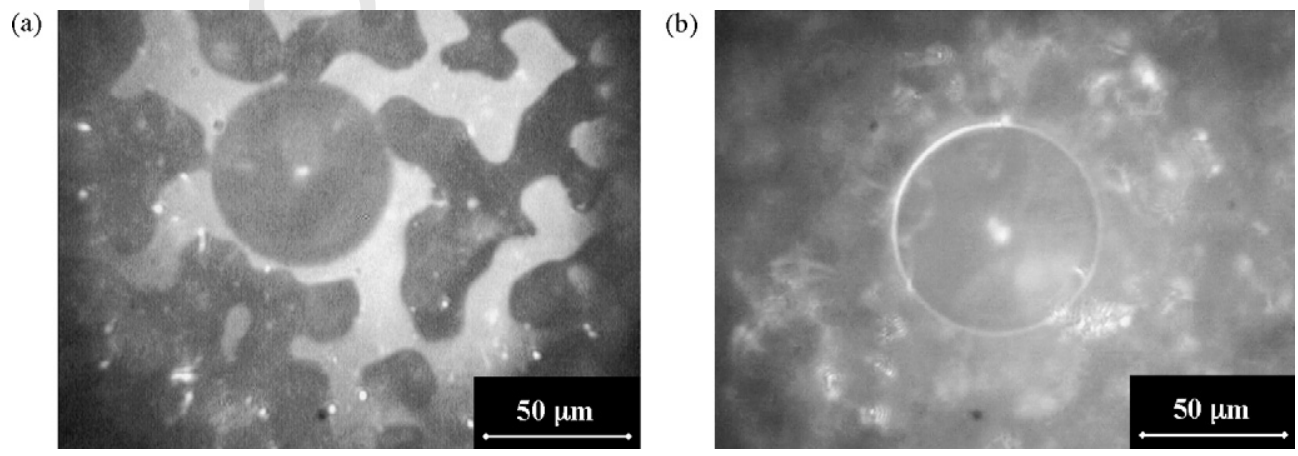

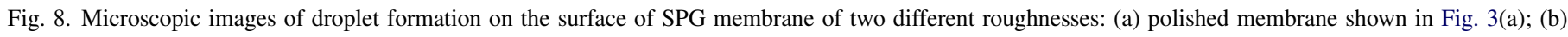
unpolished membrane shown in Fig. 3(b).

Please cite this article in press as: G.T. Vladisavljević et al., Shirasu Porous Glass membrane emulsification: Characterisation of membrane structure by high-resolution X-ray microtomography and microscopic observation of droplet formation in real time, J. Membr. Sci. (2007), doi:10.1016/j.memsci.2007.06.067 


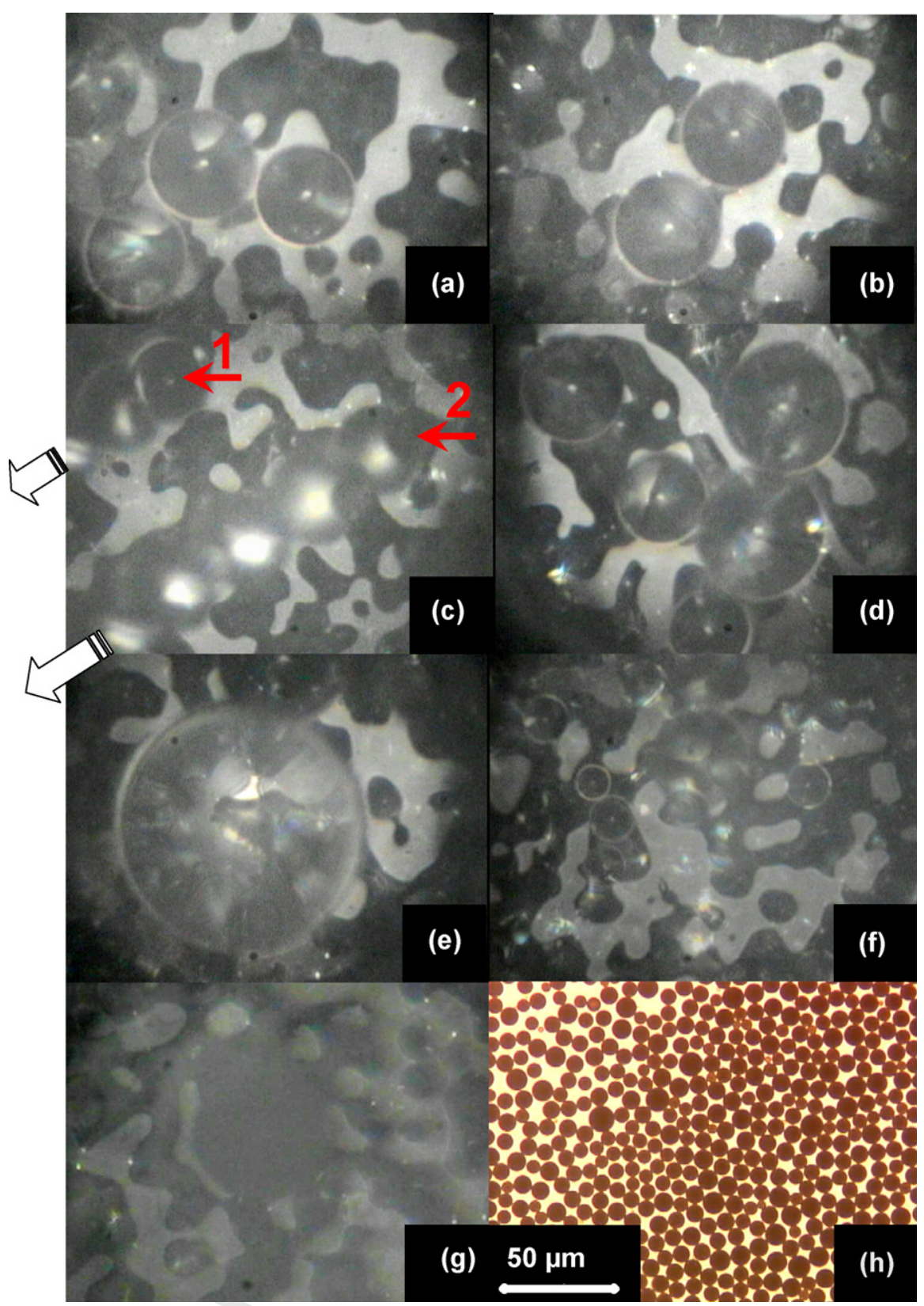

Fig. 9. Microscopic images of droplet formation on the surface of polished SPG membrane with $d_{\mathrm{p}}=15 \mu \mathrm{m}$ : (a) $\mathrm{O} / \mathrm{W}$ emulsion, Tween $80, Q_{\mathrm{d}}=0.3 \mathrm{ml} \mathrm{h}^{-1}$, $Q_{\mathrm{c}}=100 \mathrm{ml} \mathrm{h}^{-1}$; (b) O/W emulsion, Tween $80, Q_{\mathrm{d}}=0.2 \mathrm{ml} \mathrm{h}^{-1}, Q_{\mathrm{c}}=100 \mathrm{ml} \mathrm{h}^{-1}$; (c) O/W emulsion, SDS, $Q_{\mathrm{d}}=4 \mathrm{ml} \mathrm{h}^{-1}, Q_{\mathrm{c}}=700 \mathrm{ml} \mathrm{h}^{-1}$. The direction of continuous phase velocity is indicated with large arrow and the location of active pores 1 and 2 is indicated with small arrow; (d) O/W emulsion, Tween $80, Q_{\mathrm{d}}=0.2 \mathrm{ml} \mathrm{h}^{-1}$, $Q_{\mathrm{c}}=100 \mathrm{ml} \mathrm{h}^{-1}$; (e) O/W emulsion, Tween $80, Q_{\mathrm{d}}=0.2 \mathrm{ml} \mathrm{h}^{-1}, Q_{\mathrm{c}}=100 \mathrm{ml} \mathrm{h}^{-1}$; (f) O/W emulsion, SDS, $Q_{\mathrm{d}}=4 \mathrm{ml} \mathrm{h}^{-1}, Q_{\mathrm{c}}=700 \mathrm{ml} \mathrm{h}-1$; (g) W/O/W emulsion, Tween $Q_{\mathrm{d}}=0.1 \mathrm{ml} \mathrm{h}^{-1}, Q_{\mathrm{c}}=100 \mathrm{ml} \mathrm{h}^{-1}$; (h) multiple emulsion droplets collected after emulsification.

Rayleigh instability, which predicts that an oil thread of radius $R<R_{\mathrm{p}}$ will break up inside the pores of radius $R_{\mathrm{p}}$ into smaller fragments of length $\lambda$ to minimize surface energy, where $\lambda=2 \pi R$ is the dominant wavelength of the instability. It is easy to show that the ratio of the radius of the final droplets to the pore radius is smaller than $(3 \pi / 2)^{1 / 3}(=1.68)$, which means that normally this mechanism does not occur in the direct membrane emulsification, in which the radius of the final droplets to the pore radius is higher than 2 and often higher than 3.

Large droplets shown in Fig. 9(e) were formed at the pore outlets at the oil flow rates higher than a critical flow rate through a pore. When multiple $\mathrm{W} / \mathrm{O} / \mathrm{W}$ emulsion droplets were formed, the membrane surface was covered by a thin continuous layer of the dispersed phase (W/O emulsion), which is noticeable in Fig. $9(\mathrm{~g})$ because a W/O emulsion is non-transparent, unlike a pure oil.

\subsection{Droplet formation time}

The droplets have been formed and detached in regular time intervals at the same active pore, but this time interval showed significant variations over the membrane surface, as can be seen

Please cite this article in press as: G.T. Vladisavljević et al., Shirasu Porous Glass membrane emulsification: Characterisation of membrane structure by high-resolution X-ray microtomography and microscopic observation of droplet formation in real time, J. Membr. Sci. (2007), doi:10.1016/j.memsci.2007.06.067 


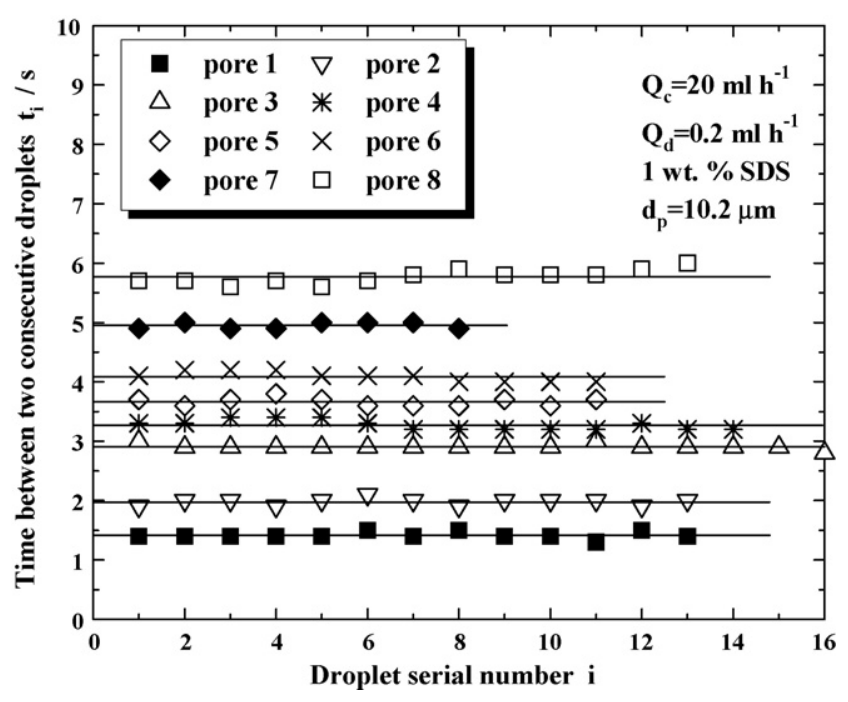

Fig. 10. Time intervals between generation of two consecutive droplets at eight randomly taken active pores (O/W emulsion, emulsifier: $1 \mathrm{wt} \% \mathrm{SDS})$.

in Fig. 10 for eight randomly chosen active pores. The pores have been observed during the same experiment in which the oil flow rate through the membrane was maintained constant at $0.2 \mathrm{ml} \mathrm{h}^{-1}$. As can be seen, the time interval between the breakup of two consecutive droplets from the same pore was virtually the same, but varied from 1.4 to $5.8 \mathrm{~s}$ for different pores. Only active pores has been taken into account in Fig. 8, but in fact the great majority of the pores was inactive under the conditions specified.

As shown in Fig. 11, the droplets formed at the same active pore had almost the same diameter, but this diameter varied over a relatively wide range for different pores. As a rule, the longer the time interval between two consecutive droplets formed at the same pore, the greater the droplet diameter. It means that the mean dispersed phase flow rate through each active pore

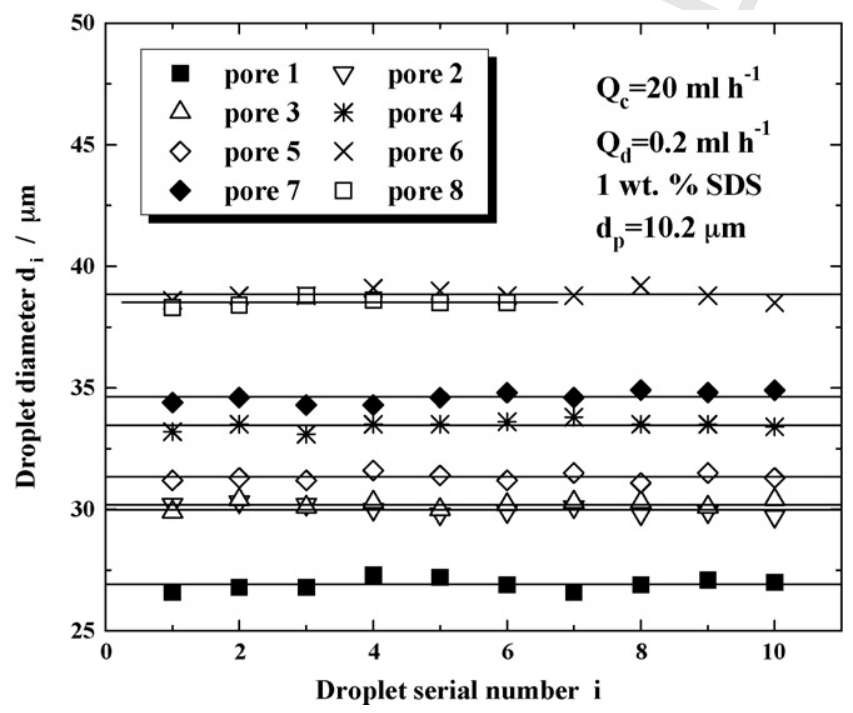

Fig. 11. Variation in diameters of the droplets formed consecutively at eight randomly chosen active pores. The pores are the same as in Fig. $10\left(J_{\mathrm{d}}=11 \mathrm{~m}^{-2} \mathrm{~h}^{-1}\right.$, $\left.\mathrm{CV}=11.7 \%, d_{\mathrm{n}}=31.4 \mu \mathrm{m}, k=1 \%\right)$. The $k$-value was calculated using Eq. (4). tends to be constant. As Fig. 10 shows, the shortest time interval between two consecutive droplets was found for pore 1 and the smallest droplets were formed at that pore, as can be seen in Fig. 11. The coefficient of variation CV for all droplets in Fig. 11 was $11.7 \%$ which is within a range of $10-17 \%$ typically reported for direct SPG membrane emulsification [38,32]. On the other hand, droplets formed at the same pore had a $\mathrm{CV}$ between 0.5 and $1 \%$, which is a typical $\mathrm{CV}$ for droplets formed in flow focusing microfluidic devices [39]. It can be concluded that droplets formed at the same pore of SPG membrane are highly monodisperse and that the droplet polydispersity of over $10 \%$ is a consequence of the fact that differently sized droplets are formed at different pores. For the droplets considered in Fig. 11, Eq. (1) gives $d_{\mathrm{n}}=31.4 \mu \mathrm{m}$ and thus $d_{\mathrm{n}} / d_{\mathrm{p}}=3.1$, which agrees very well with previously reported $d_{\mathrm{n}} / d_{\mathrm{p}}$ values for SPG membrane $[3,8]$. The proportion of active pores $k$ for the conditions given in Fig. 11 was 1\%, calculated from Eq. (4). Using equation: $k=J_{\mathrm{d}} \eta_{\mathrm{d}} R_{\mathrm{m}} / \Delta p_{\mathrm{tm}}$, the fraction of active pores in cross-emulsification using SPG membrane with $d_{\mathrm{p}}=4.8 \mu \mathrm{m}$ at $\Delta p_{\mathrm{tm}} / p_{\text {cap }}=1.5-2$ was estimated to be $1.3 \%$ [7]. A reason for a low proportion of active pores in this work was a low transmembrane pressure.

\subsection{Effect of emulsifier type on droplet formation behaviour}

The choice of emulsifier is often critical for the success of membrane emulsification $[9,40]$. A chosen emulsifier should rapidly adsorb to the newly formed oil-water interface to reduce the interfacial tension, but it should not adsorb to the membrane surface, because it would lead to its wetting with the dispersed phase, due to switch in membrane polarity from hydrophilic to hydrophobic and vice versa. A hydrophilic (untreated) SPG membrane has a negative surface potential of -15 to $-35 \mathrm{mV}$ within a $\mathrm{pH}$ range of $2-8$, due to dissociation of acidic silanol groups. Therefore, in order to prevent electrostatic deposition of emulsifier on the surface of a hydrophilic SPG membrane, the use of cationic emulsifiers such as alkyl-substituted quaternary ammonium salts must be avoided [3]. In this work, we have observed generation of oil droplets stabilised by $1 \mathrm{wt} \%$ SDS or Tween 80 to find out if there is any difference in droplet formation behaviour between non-ionic and anionic surfactants. As shown in Fig. 12, for the same oil flux, the frequency of droplet generation was substantially greater for SDS than for Tweenstabilised droplets. According to Eq. (4), it indicates that the proportion of active pores was lower for SDS-stabilised emulsions. It is interesting to note that over the flux range between 1 and $101 \mathrm{~m}^{-2} \mathrm{~h}^{-1}$, a linear relationship was observed between $J_{\mathrm{d}}$ and $v$, reflecting the fact that under these conditions the proportion of active pores was independent on $J_{\mathrm{d}}$. At the same oil flux and emulsifier type, $v$ was independent on the mean pore size and the roughness of the membrane surface.

The SDS-stabilised droplets were detached from the pores as soon as they were formed, due to strong electrostatic repulsions between anionic droplets and the negatively charged surface of the SPG membrane. The non-ionic Tween 80-stabilised droplets were kept attached to the membrane surface after formation, 


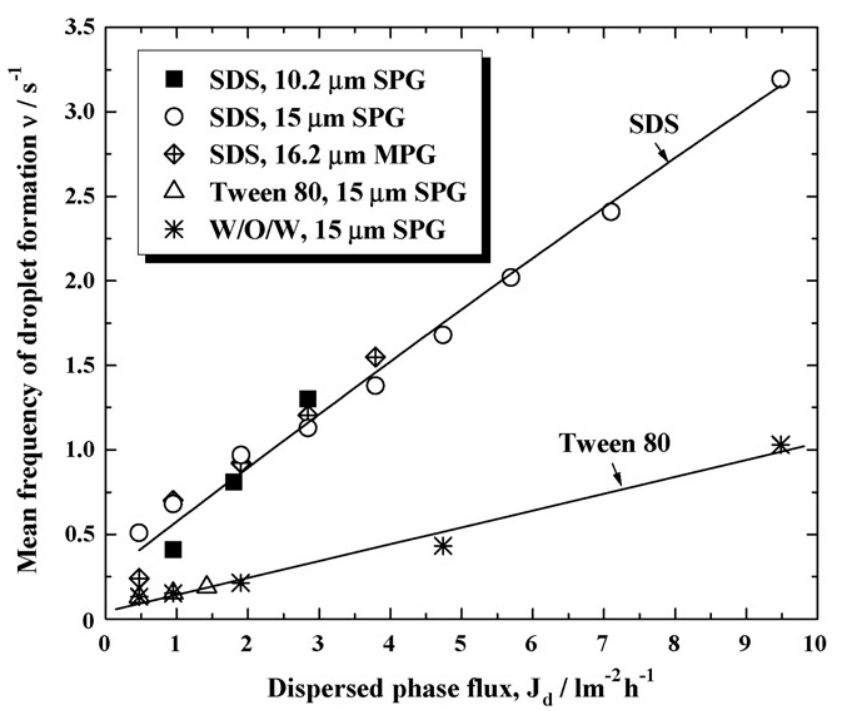

Fig. 12. The effect of dispersed phase flux on the mean frequency of droplet generation for different emulsion formulations.

until they were pushed away by the next droplet formed at the same pore. It was a consequence of negligible surface charge of Tween 80-stabilised droplets in comparison with droplets stabilised by SDS. For example, the $\xi$-potential of SDS-stabilised corn oil droplets in an aqueous solution containing $0.2 \mathrm{wt} \%$ SDS, $10 \mathrm{mM} \mathrm{NaCl}$, and $100 \mathrm{mM}$ acetic acid at $\mathrm{pH} 3$ was found to be $-105 \mathrm{mV}$ [41]. The $\xi$-potential of corn oil droplets stabilised by Tween 80 at the same conditions was found to be $-12 \mathrm{mV}$, mostly due to the presence of small amount of free fatty acids in oil [41].

Due to the existence of strong electrostatic repulsion between the droplets and membrane surface that assists in droplet detachment from the pores, it is reasonable to expect that under the same conditions the resultant SDS-stabilised droplets will be smaller than the droplets stabilised by Tween 80 . This predic-

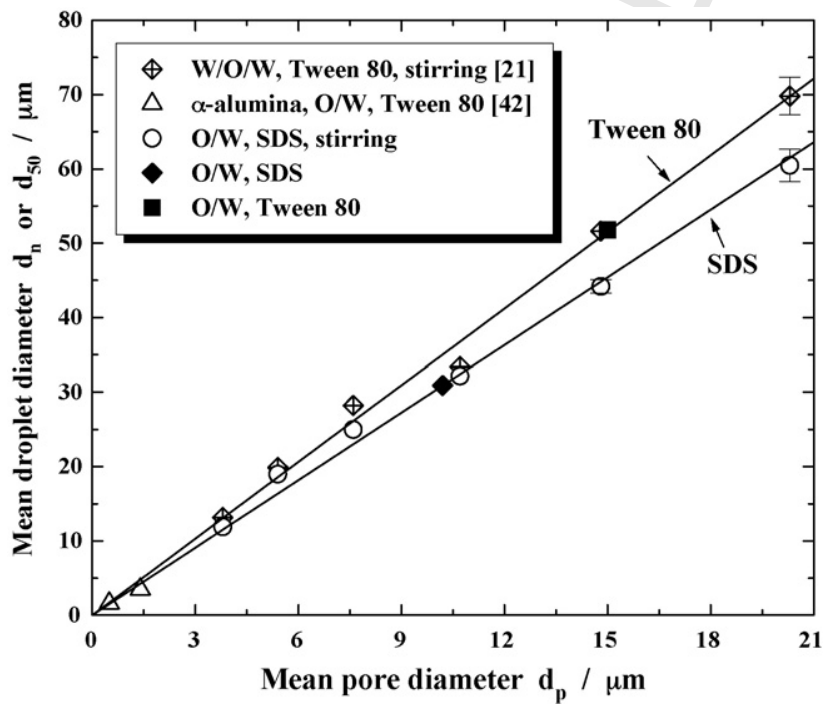

Fig. 13. The effect of mean pore size of SPG membrane on the mean particle size in the presence of $0.5 \Lambda_{\mathrm{wt}} \%$ SDS or Tween 80 for various experimental set-ups [42]. tion has been confirmed in Fig. 13 for different experimental set-ups, e.g. tubular cross-flow membrane, flat membrane disks and SPG tubes in a stirred vessel. As expected, the mean particle size $d_{\mathrm{n}}$ was proportional to the mean pore size $d_{\mathrm{p}}$ for both emulsifiers, but for SDS the value of $d_{\mathrm{n}} / d_{\mathrm{p}}$ was 3.02 , whereas $d_{\mathrm{n}} / d_{\mathrm{p}}=3.43$ for Tween 80. All experiments in Fig. 13 have been carried out at the transmembrane pressures slightly higher than the capillary pressure, therefore in the dripping regime, where resultant droplet size is not critically dependent on shear rate at the membrane surface, but primarily on the pore size and the choice of emulsifier.

\section{Conclusions}

The microstructure of Shirasu Porous Glass (SPG) membrane has been investigated using metallographic microscope and high-resolution X-ray microtomography (XMT). The porosity in 600 cross sections of SPG membrane analysed by highresolution XMT was found to range between 52.5 and $57.4 \%$ with a mean value of $55.1 \%$, which corresponded very well with Hg-porosimetry data. The XMT data indicates that SPG membrane has very uniform porosity throughout the whole cross-section without any internal defects such as cracks or large voids, which is of high relevance in membrane emulsification. The mean pore size determined by high-resolution XMT was overestimated by $20-40 \%$ due to low pixel resolution and the presence of many pore junctions. For making high-quality images with metallographic microscope, the surface of SPG membrane should be finely polished with diamond paste. No droplet coalescence was observed even if droplets contacted each other at the membrane surface. When multiple $\mathrm{W} / \mathrm{O} / \mathrm{W}$ emulsion droplets have been formed, the membrane surface was covered by a thin layer of the dispersed phase (W/O emulsion).

The droplets have been detached from the same pore in regular time intervals, but this time interval showed significant variations for different active pores. The proportion of active pores was $1 \%$ and independent on the transmembrane flux in the range of oil fluxes investigated. The droplet production rate was substantially higher for SDS- than for Tween 80-stabilised droplets, indicating that the proportion of active pores was lower for SDS than for Tween 80 stabilised-emulsions. The SDS stabilised-droplets were detached from the pores as soon as they were formed, due to strong electrostatic repulsions between the droplets and negatively charged SPG surface. The Tween 80 stabilised-droplets were kept attached to the membrane surface after formation, before being pushed by the next droplet formed at the same pore. Under the same conditions the SDS-stabilised droplets were smaller then the droplets stabilised by Tween 80 .

\section{Acknowledgements}

Goran T. Vladisavljević wishes to thank the Japan Society for the Promotion of Science, Tokyo (the postdoctoral fellowship ID No. P-02475) for the financial support of this work. The support from the Royal Society (International short fellowship) for microtomographic work is also highly appreciated. 
List of symbols

$A_{\mathrm{m}} \quad$ cross-sectional area of membrane $\left(\mathrm{m}^{2}\right)$

$d_{i} \quad$ mean droplet diameter at the $i$ th active pore (m)

$d_{\mathrm{n}} \quad$ Number-weighted mean droplet diameter $(\mathrm{m})$

$d_{\mathrm{p}} \quad$ mean pore size of membrane $(\mathrm{m})$

$J_{\mathrm{d}} \quad$ dispersed phase flux $\left(\mathrm{m} \mathrm{s}^{-1}\right)$

$k \quad$ proportion of active pores $\left(N_{\mathrm{a}} / N\right)$

$n \quad$ number of active pores observed

$N \quad$ total number of pores

$N_{\mathrm{a}} \quad$ number of active pores

$p_{\text {cap }} \quad$ capillary pressure $(\mathrm{Pa})$

$\Delta p_{\text {tm }} \quad$ transmembrane pressure $(\mathrm{Pa})$

$Q_{\mathrm{c}}$ flow rate of continuous phase above membrane $\left(\mathrm{m}^{3} \mathrm{~s}^{-1}\right)$

$Q_{\mathrm{d}} \quad$ flow rate of dispersed phase through membrane $\left(\mathrm{m}^{3} \mathrm{~s}^{-1}\right)$

$R_{\mathrm{m}} \quad$ membrane resistance $\left(\mathrm{m}^{-1}\right)$

$t \quad$ time (s)

$z \quad$ coordinate perpendicular to membrane cross sections (m)

\section{Greek symbols}

$\varepsilon \quad$ porosity of membrane wall

$\eta_{\mathrm{d}} \quad$ viscosity of dispersed phase (Pas)

$v \quad$ mean frequency of droplet generation $\left(\mathrm{s}^{-1}\right)$

$\xi \quad$ mean tortuosity factor of pores

\section{Subscript}

$i \quad$ refers to $i$ th active pore or $i$ th droplet

\section{References}

[1] T. Nakashima, M. Shimizu, Porous glass from calcium alumino borosilicate glass, Ceram. Jpn. 21 (1986) 408.

[2] T. Nakashima, M. Shimizu, M. Kawano, Articles of porous glass and process for preparing the same, US Patent 4,657,875 (1987).

[3] T. Nakashima, M. Shimizu, M. Kukizaki, Membrane Emulsification Operation Manual, Department of Chemistry, Industrial Research Institute of Miyazaki Prefecture, Miyazaki, 1991.

[4] G.T. Vladisavljević, H. Schubert, Preparation and analysis of oil-in-water emulsions with a narrow droplet size distribution using Shirasu-porousglass (SPG) membranes, Desalination 144 (2002) 167.

[5] M. Shimizu, T. Nakashima, M. Kukizaki, Particle size control of W/O emulsion by means of osmotic pressure as driving force, Kag. Kog. Ronbunshu 28 (2002) 304.

[6] M. Shimizu, T. Nakashima, M. Kukizaki, Preparation of W/O emulsion by membrane emulsification and optimum conditions for its monodispersion, Kag. Kog. Ronbunshu 28 (2002) 310.

[7] G.T. Vladisavljević, H. Schubert, Influence of process parameters on droplet size distribution in SPG membrane emulsification and stability of prepared emulsion droplets, J. Membr. Sci. 225 (2003) 15.

[8] G.T. Vladisavljević, U. Lambrich, M. Nakajima, Production of O/W emulsions using SPG membranes, ceramic $\alpha-\mathrm{Al}_{2} \mathrm{O}_{3}$ membranes, microfluidizer and a microchannel plate: a comparative study, Colloids Surf. A 232 (2004) 199.

[9] G.T. Vladisavljević, J. Surh, J.D. McClements, Effect of emulsifier type on droplet disruption in repeated Shirasu Porous Glass membrane homogenization, Langmuir 22 (2006) 4526.

[10] S. van der Graaf, C.G.P.H. Schroën, R.M. Boom, Preparation of double emulsions by membrane emulsification-a review, J. Membr. Sci. 251 (2005) 7.
[11] S.M. Joscelyne, G. Trägårdh, Membrane emulsification-a literature review, J. Membr. Sci. 169 (2000) 107.

[12] T. Nakashima, M. Shimizu, M. Kukizaki, Particle control of emulsion by membrane emulsification and its applications, Adv. Drug Deliv. Rev. 45 (2000) 47.

[13] G.T. Vladisavljević, R.A. Williams, Recent developments in manufacturing emulsions and particulate products using membranes, Adv. Colloid Interf. Sci. 113 (2005) 1.

[14] U. Lambrich, G.T. Vladisavljević, Emulgieren mit mikrostrukturierten Systemen, Chem. Eng. Technol. 76 (2004) 376.

[15] A.J. Gijsbertsen-Abrahamse, A. van der Padt, R.M. Boom, Status of crossflow membrane emulsification and outlook for industrial application, J. Membr. Sci. 230 (2004) 149.

[16] G. De Luca, E. Drioli, Force balance conditions for droplet formation in cross-flow membrane emulsifications, J. Colloid Interf. Sci. 294 (2006) 436.

[17] R.A. Williams, S.J. Peng, D.A. Wheeler, N.C. Morley, D. Taylor, M. Whalley, D.W. Houldsworth, Controlled production of emulsions using a crossflow membrane, Chem. Eng. Res. Des. 76A (1998) 902.

[18] S.R. Kosvintsev, G. Gasparini, R.G. Holdich, I.W. Cumming, M.T. Stillwell, Liquid-liquid membrane dispersion in a stirred cell with and without controlled shear, Ind. Eng. Chem. Res. 44 (2005) 9323.

[19] M. Rayner, G. Trägårdh, C. Trägårdh, The impact of mass transfer and interfacial expansion rate on droplet size in membrane emulsification processes, Colloids Surf. A 266 (2005) 1.

[20] G.T. Vladisavljević, M. Shimizu, T. Nakashima, Preparation of monodisperse multiple emulsions at high production rates by multi-stage premix membrane emulsification, J. Membr. Sci. 244 (2004) 97.

[21] G.T. Vladisavljević, M. Shimizu, T. Nakashima, Production of multiple emulsions for drug delivery systems by repeated SPG membrane homogenization: influence of mean pore size, interfacial tension and continuous phase viscosity, J. Membr. Sci. 284 (2006) 373.

[22] J. Surh, G.T. Vladisavljević, S. Mun, D.J. McClements, Preparation and characterization of water/oil and water/oil/water emulsions containing biopolymer-gelled water droplets, J. Agric. Food Chem. 55 (2007) 175.

[23] M. Kukizaki, M. Goto, Preparation and evaluation of uniformly sized solid lipid microcapsules using membrane emulsification, Colloids Surf. A 293 (2007) 87.

[24] S. Omi, K.I. Katami, T. Taguchi, K. Kaneko, M. Iso, Synthesis of uniform PMMA microspheres employing modified SPG (Shirasu Porous Glass) emulsification technique, J. Appl. Polym. Sci. 57 (1995) 1013.

[25] K. Kandori, K. Kishi, T. Ishikawa, Preparation of uniform silica hydrogel particles by SPG filter emulsification method, Colloids Surf. 62 (1992) 259.

[26] M. Shimizu, K. Torigoe, I. Akazaki, T. Nakashima, Preparation of monodispersed solder microspheres by membrane emulsification, in: Proceedings of the 36th SPG Forum "Various Applications of Membrane and Particles in Healthcare Fields", Miyazaki, December 6-7, 2001, p. 78.

[27] E. Toorisaka, H. Ono, K. Arimori, N. Kamiya, M. Goto, Hypoglycemic effect of surfactant-coated insulin solubilized in a novel solid-in-oil-inwater (S/O/W) emulsion, Int. J. Pharm. 252 (2003) 271.

[28] M. Kukizaki, M. Goto, Size control of nanobubbles generated from Shirasuporous-glass (SPG) membranes, J. Membr. Sci. 281 (2006) 386.

[29] T. Kawakatsu, Y. Kikuchi, M. Nakajima, Regular-sized cell creation in microchannel emulsification by visual microprocessing method, J. Am. Oil Chem. Soc. 74 (1997) 317.

[30] A.J. Abrahamse, R. van Lierop, R.G.M. van der Sman, A. van der Padt, R.M. Boom, Analysis of droplet formation and interactions during cross-flow membrane emulsification, J. Membr. Sci. 204 (2002) 125.

[31] I. Kobayashi, M. Yasuno, S. Iwamoto, A. Shono, K. Satoh, M. Nakajima, Microscopic observation of emulsion droplet formation from a polycarbonate membrane, Colloids Surf. A 207 (2002) 185.

[32] M. Yasuno, M. Nakajima, S. Iwamoto, T. Maruyama, S. Sugiura, I. Kobayashi, A. Shono, K. Satoh, Visualization and characterization of SPG membrane emulsification, J. Membr. Sci. 210 (2002) 29.

[33] G.T. Vladisavljević, M. Shimizu, T. Nakashima, Permeability of hydrophilic and hydrophobic Shirasu-porous-glass (SPG) membranes to pure liquids and its microstructure, J. Membr. Sci. 250 (2005) 69. 
[34] T. Nakashima, M. Shimizu, Liquid permeability of porous glass membrane and its microstructure, J. Ceram. Soc. Jpn. 101 (1993) 528.

[35] R.A. Williams, X. Jia, Tomographic imaging of particulate materials, Adv. Powder Technol. 14 (2003) 1.

[36] C. Selomulya, T.M. Tran, R.A. Williams, R. Amal, An integrated methodology to evaluate permeability based on measured microstructures, AIChE J. 52 (2006) 3394.

[37] M. Kukizaki, M. Goto, Preparation and characterization of a new asymmetric type of Shirasu porous glass (SPG) membrane used for membrane emulsification, J. Membr. Sci., in press-

[38] H. Yuyama, T. Watanabe, G.H. Ma, M. Nagai, S. Omi, Preparation and analysis of uniform emulsion droplets using SPG membrane emulsification technique, Colloids Surf. A 168 (2000) 159.
[39] A.S. Utada, E. Lorenceau, D.R. Link, P.D. Kaplan, H.A. Stone, D.A. Weitz, Monodisperse double emulsions generated from a microcapillary device, Science 308 (2005) 537.

[40] I. Kobayashi, M. Nakajima, S. Mukataka, Preparation characteristics of oil-in-water emulsions using differently charged surfactants in straightthrough microchannel emulsification, Colloids Surf. A 229 (2003) 33.

[41] G.T. Vladisavljević, D.J. McClements, unpublished material.

[42] G.T. Vladisavljević, H. Schubert, Preparation of emulsions with a narrow particle size distribution using microporous $\alpha$-alumina membranes, J. Dispers. Sci. Technol. 24 (2003) 811.

Please cite this article in press as: G.T. Vladisavljević et al., Shirasu Porous Glass membrane emulsification: Characterisation of membrane structure by high-resolution X-ray microtomography and microscopic observation of droplet formation in real time, J. Membr. Sci. (2007), doi:10.1016/j.memsci.2007.06.067 